Comparative and Functional Genomics

Comp Funct Genom 2005; 6: 344.

Published online in Wiley InterScience (www.interscience.wiley.com). DOl: 10.1002/cfg.495

\title{
Editorial
}

\section{Goodbye to CFG}

Sadly, I am writing this Editorial to let you know of our decision to close Comparative and Functional Genomics as of this issue.

Unfortunately, despite much hard work by the entire Editorial Board and the team at Wiley, $C F G$ has not achieved what we had hoped and we feel that no amount of effort will be enough to rectify this. This will be the final issue of the journal. However, its archive will be maintained and all the material published in $C F G$ will continue to be made available from the Journal's website.
I would like to take this opportunity to thank the Section Editors and Editorial Board members, on behalf of Wiley and myself, for all their work and support for $C F G$.

I hope that you have enjoyed reading $C F G$ and send our thanks to all of you who contributed articles to the journal or assisted in the refereeing process.

Steve Oliver 

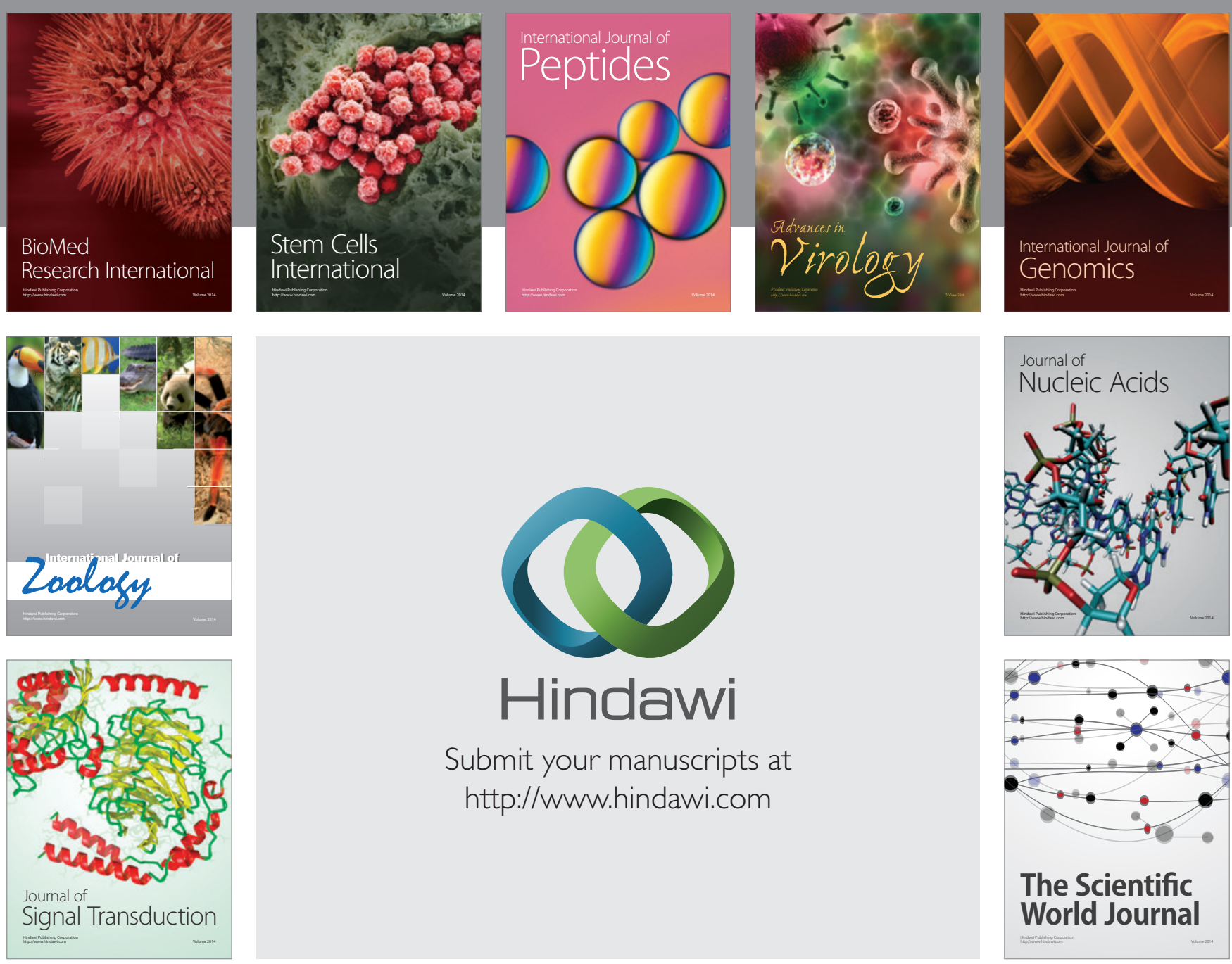

Submit your manuscripts at

http://www.hindawi.com
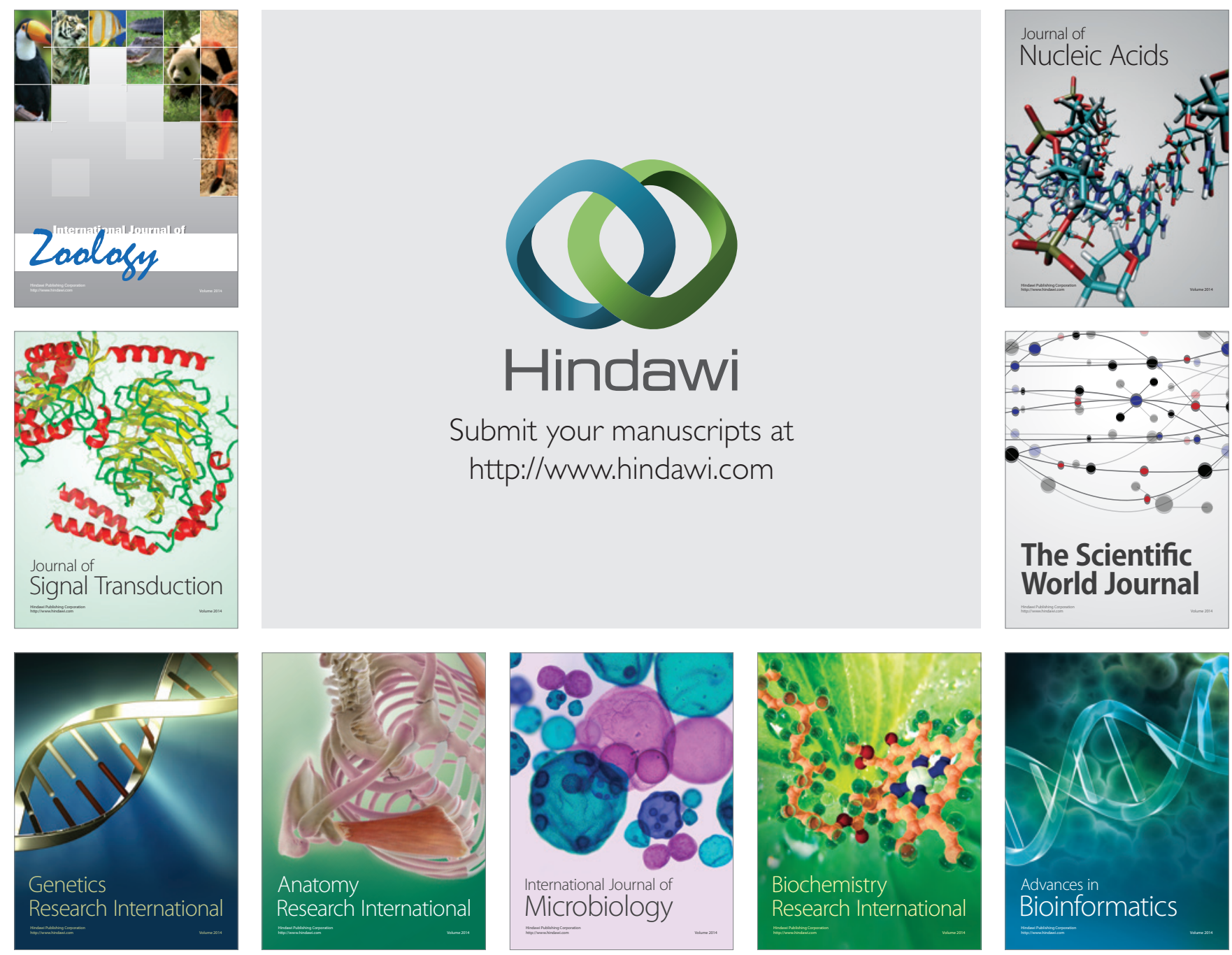

The Scientific World Journal
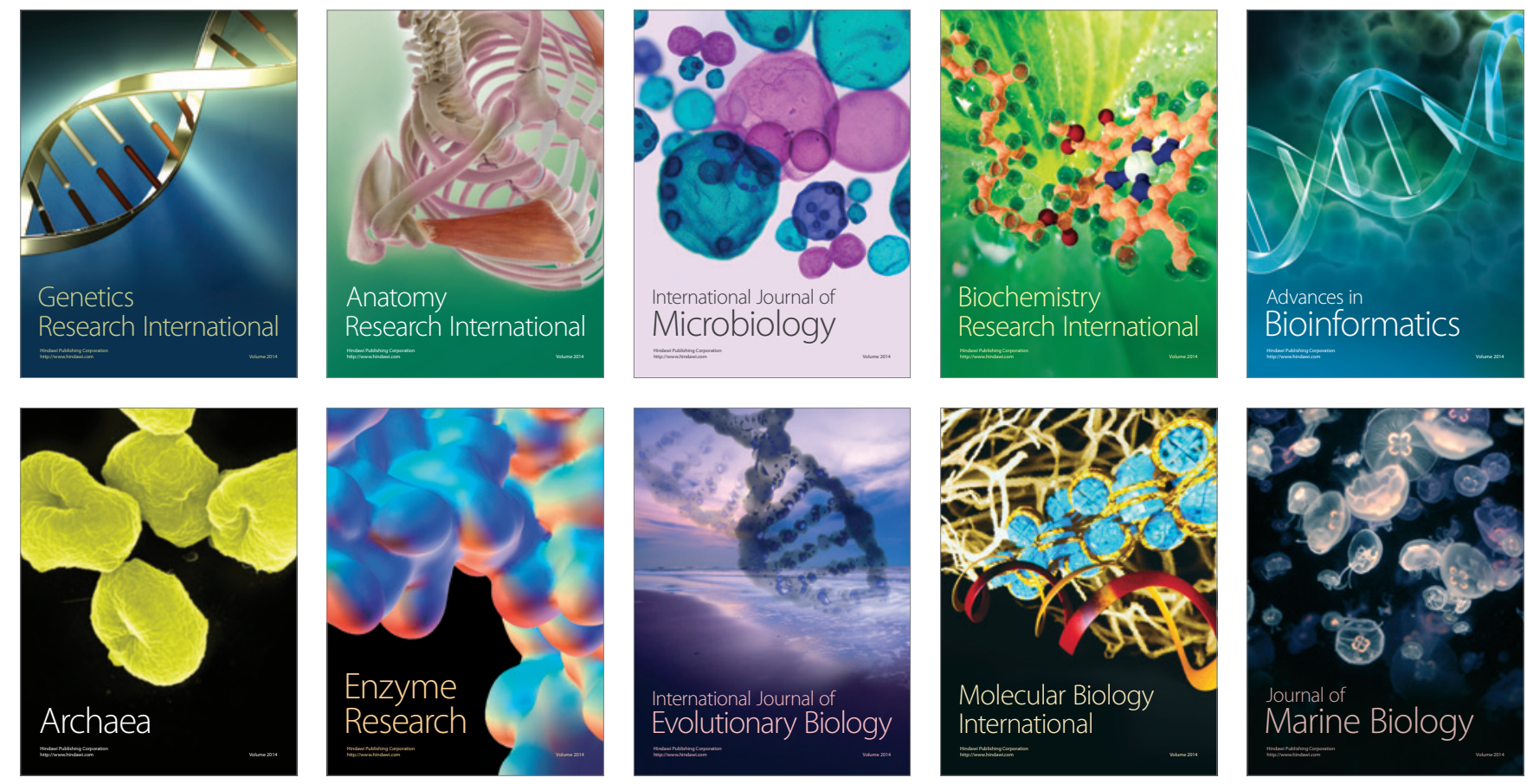